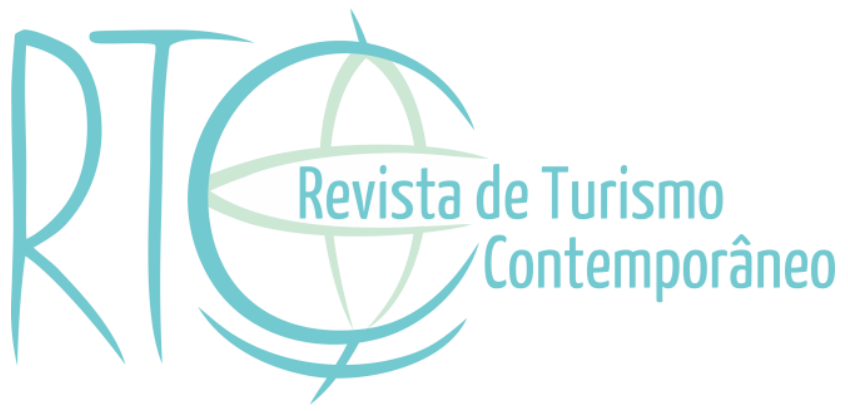

\title{
Voluntariado e democratização no acesso ao turismo por meio da plataforma digital Worldpackers
}

\section{Volunteering and democratization in access to tourism through the Worldpackers digital platform}

\section{Tauwan Berti}

Bacharel em Relações Públicas pela Universidade Federal do Pampa - UNIPAMPA, São Borja/RS, Brasil

E-mail: tauwanbrp@gmail.com

Larissa Conceição dos Santos

Professora Adjunta na Universidade Federal do Pampa - UNIPAMPA, São Borja/RS, Brasil E-mail: larissasantos@unipampa.edu.br 


\section{RESUMO}

O presente estudo teve por finalidade estudar as possibilidades de democratização do turismo através da plataforma Worldpackers, uma plataforma digital que facilita a realização de viagens, levando em conta três formas de voluntariado e tendo como ênfase a troca de habilidades por hospedagem. Como abordagem teórica, o trabalho aproxima os campos do turismo (Netto \& Gaeta, 2010; Goeldner, Ritchie \& Mcintosh, 2002) em seus aspectos sociais, culturais e econômicos, e da comunicação Corrêa (2005), o cenário digital e a emergência de dispositivos como as plataformas de viagens/turismo, e fundamenta-se ainda em perspectivas de estudo da democracia (Habermas 1995; Santos, 2002). O percurso metodológico estruturou-se a partir de pesquisa exploratória Gil (2008), pesquisa bibliográfica Marconi e Lakatos (2003), o estudo de caso com caráter qualitativo Robert Yin (2001), tendo como objeto a plataforma digital Worldpackers, como recorte, a atuação desta organização no Brasil e foco analítico na atuação da plataforma, isto é, a comunicação e estratégias utilizadas com os diversos públicos, visando entender como possibilitam o acesso ao turismo. Para a coleta de dados realizou-se entrevista com um dos fundadores da Worldpackers, bem como aplicou-se um questionário direcionado aos viajantes que já utilizam a plataforma. Como resultados, observa-se a relação entre o surgimento destas plataformas e a busca pelo turismo de experiência, o potencial de outras iniciativas no cenário digital que possibilitam um maior acesso às viagens e, consequentemente, uma possível democratização na prática turística.

Palavras-chave: Comunicação Digital. Democracia. Turismo.

\section{ABSTRACT}

The current study aimed to study the possibilities of tourism democratization through the platform Worldpackers, a digital platform that facilitates travelling, taking into consideration three forms of volunteering and focusing on the exchange of one's skills for room and board. On the theoretical approach, the work connects the tourism fields (Netto \& Gaeta, 2010; Goeldner, Ritchie \& Mcintosh, 2002) in their social, cultural and economical aspects, and the communication fields Côrrea (2005), the digital scenario and the emergency of devices as those travel/tourism platforms, and even based on the perspective of democracy studies (Habermas 1995; Santos, 2002). The methodological path was structured from a exploratory research Gil (2008), bibliographic research Marconi e Lakatos (2003), the study of a case with a qualitative aspect Robert Yin (2001), with the platform Worldpackers being the subject, and as the outline, the practice of this organization in Brazil and analytical focus on the platform's practice, that is, the communication and strategies used within multi publics, seeking to understand how to provide the access to tourism. For data gathering it was performed an interview with one of the founders of the platform Worldpackers, as well as a questionnaire targeting the travelers that already use the platform. As results, we noted a relation between the appearance of these platforms and the search for the experienced tourism, the potential of other initiatives in the digital scenario that allow a greater access to travels and, consequently, a possible democratization in the tourist practice.

Keywords: Digital Communication. Democracy. Tourism. 


\section{INTRODUÇÃO}

Com o avanço dos meios de comunicação ao longo dos anos, observa-se a emergência de novas formas de comunicar, de novos espaços de sociabilidade e, assim, de outras ambiências. Nesse contexto, destaca-se a comunicação digital e as alternativas decorrentes de seu surgimento, como, por exemplo, o desenvolvimento das plataformas digitais no âmbito do world wide web.

Entre elas, pretende-se aqui observar a Worldpackers ${ }^{I}$, uma plataforma inteiramente digital que se apresenta como uma possibilidade aos viajantes que queiram viajar em troca de habilidades e partilha de conhecimentos, por meio do voluntariado. A plataforma surgiu em 2014, portanto, o chamado "intercâmbio de trabalho", que consiste em uma alternativa de voluntariado oferecida pela Worldpackers - visando proporcionar uma experiência diferenciada de turismo - mostra-se ainda relativamente recente, e com interessantes perspectivas de investigação, como, por exemplo, pela interface entre o turismo de experiência e a comunicação digital.

O estudo tem como objetivo principal, investigar as contribuições da plataforma digital Worldpackers para a democratização do turismo, e, a partir disso, observar as novas formas de praticar o turismo que emergem a partir do digital, entendendo, por consequência, como as estratégias de comunicação que a plataforma utiliza com os seus públicos possibilitam ou favorecem o acesso à viagens e ao turismo. Como processo metodológico, realizou-se uma pesquisa exploratória, apoiada em métodos bibliográficos, aproximando as perspectivas teóricas da comunicação digital (Corrêa, 2005), do turismo (Netto \& Gaeta, 2010) e da democracia (Santos, 2002; Habermas, 1995).

Além disso, realizou-se um estudo de caso com caráter qualitativo, tendo como objeto a plataforma Worldpackers. Com relação às técnicas de coleta de dados, optou-se por uma entrevista com o membro fundador da Worldpackers, visando compreender o surgimento da plataforma e a sua relação com o turismo, bem como, um questionário destinado aos viajantes/voluntários, com o intuito de investigar as possibilidades de democratização turística, a partir da experiência com esse novo modelo de viagens/turismo colaborativo que surge no ambiente digital.

O interesse em investigar a plataforma Worldpackers como objeto de estudo, surge a partir de uma experiência pessoal de voluntariado, através do intercâmbio de trabalho no litoral de Santa Catarina/SC, em que foi possível observar as alternativas que a plataforma oferece aos

\footnotetext{
${ }^{1}$ Informações disponíveis no site da Plataforma no endereço eletrônico: https:/www.worldpackers.com/pt-BR
} 
viajantes, tanto com relação à comunicação digital, como também no que diz respeito às possibilidades de voluntariado.

A partir disso, observou-se a inexistência de pesquisas relacionadas ao Worldpackers desenvolvidas pela ótica da comunicação digital. Bem como, identificou-se o potencial analítico de estudos destas plataformas digitais, seja pela perspectiva turística ou comunicacional. Nesse sentido, a investigação aqui apresentada desenvolve-se no escopo do campo das ciências da comunicação e aproxima-se dos estudos de turismo, em especial aqueles de turismo de experiência (Netto \& Gaeta, 2010), visando observar tais possibilidades de experimentação turísticas pelo prisma da comunicação digital (Corrêa, 2005).

Assim, espera-se que o trabalho possa contribuir à reflexão sobre as plataformas emergentes e o papel da comunicação digital no acesso e consumo turístico, por meio de modalidades alternativas, como o "intercâmbio de trabalho" oferecido pela Worldpackers.

\section{REFERENCIAL TEÓRICO}

\subsection{Democracia no contexto das práticas turísticas}

A partir do slogan difundido pela Worldpackers: "Nosso objetivo é democratizar experiências de viagem significativas por meio de uma mentalidade colaborativa" ${ }^{2}$, surgiu o interesse em observar de que maneira tais plataformas, bem como a comunicação digital empregada por elas, contribuem ou não para o acesso às viagens e, por conseguinte, se podemos depreender disso alternativas para a democratização do turismo.

Para investigar as possibilidades (ou não) da democratização do turismo através da plataforma, recorremos ao conceito proposto por Habermas (1995, p. 7), que afirma: “A democracia é valiosa não somente porque expressa a vontade da maioria, mas também porque expressa e apoia a autonomia individual em condições de interdependência". Transposta para o campo do turismo, pode-se pensar a democratização não apenas em termos de "vontade", mas no que diz respeito à garantia da autonomia individual, o direito à participação (Santos, 2002) e as possibilidades de acesso ao turismo (Brasil, 2008).

Vale destacar que no Brasil a democratização faz parte dos objetivos da Política Nacional de Turismo (Brasil, 2008), que em seu artigo $5^{\circ}$, inciso I, assume como meta "democratizar e propiciar o acesso ao turismo no País a todos os segmentos populacionais, contribuindo para a elevação do bem-estar geral”. Nessa perspectiva, reflete-se sobre o

\footnotetext{
${ }^{2}$ No original em inglês: "Our purpose is to democratize meaningful travel experiences through a collaborative mindset"
} 
surgimento de novas modalidades de viagens e de apreensão do turismo, muitas vezes de baixo custo, ou através de intercâmbios - como é o caso da AIESEC -, de redes de colaboração como proposto pelo CouchSurfing -, ou ainda de voluntariado - observado aqui no exemplo da plataforma Worldpackers - como alternativas para um turismo mais democrático.

No caso da Worldpackers, supõe-se que grande parte das pessoas que utilizam a plataforma não tenham condições financeiras para realizar viagens de alto custo, tais como aquelas ofertadas pelas tradicionais agências de viagens, na forma de pacotes all inclusive, e possam considerar o voluntariado ou o "intercâmbio de trabalho", como uma oportunidade de viajar. Ademais, entende-se que as dinâmicas ou "vivências" ofertadas pela Worldpackers também atendem a um outro interesse específico desse público viajante: a experiência, conforme revelado nas respostas ao questionário com viajante/voluntários, além de enfatizada na fala de um dos criadores da plataforma, Allan Formigoni, apresentadas a seguir, na seção 4.

\subsection{Do turismo à experiência}

O turismo, é muitas vezes associado ao deslocamento de pessoas de um lugar para outro, com algum objetivo específico, seja para visitar alguém, tirar férias, ou então, se divertir (Goeldner, Ritchie \& Mcintosh, 2002). De acordo com Goeldner et al. (2002), o turismo pode ser considerado como "pessoas que estão participando de convenções, reuniões de negócios ou algum outro tipo de atividade empresarial ou profissional, bem como aquelas que estão em viagens de estudos $[\ldots] "$.

Uma perspectiva semelhante é apresentada pela Organização Mundial do Turismo (OMT), ao afirmar que "o turismo inclui as atividades de deslocamento e permanência em locais fora do seu ambiente de residência, por período inferior a um ano consecutivo, por razões de lazer, negócios ou outros propósitos" (Goeldner et al., 2002, p. 24).

Percebe-se, a partir do exposto, que diferentes fatores podem motivar a prática turística, sejam eles relacionados ao lazer, negócios, ou mesmo por estímulo midiático:

\footnotetext{
Os seres humanos são, por natureza, curiosos em relação ao mundo em que vivem. Queremos conhecer outros lugares - como são as pessoas, suas culturas, sua flora e fauna. Atualmente níveis mais elevados de educação e a influência da televisão e os meios de comunicação combinaram-se para criar uma consciência maior a respeito do mundo (Goeldner et al., 2002, p. 18).
}

$\mathrm{Na}$ ótica desses autores, os meios de comunicação exercem uma influência direta na sociedade, influenciando, por sua vez, a área do turismo (Goeldner et al., 2002), pois, o maior 
fluxo de informações nas redes contribui para que as pessoas tenham conhecimento sobre o setor e a oferta turística, o que pode motivar o interesse pela realização de viagens.

Para Cooper, Fltecher, Wanhill, Gilbert e Shepherd (2001, p. 40) o turismo pode ser entendido como:

Uma gama de indivíduos, de negócios, de organizações e de lugares que, de alguma forma, se combinam para proporcionar uma experiência de viagem. O turismo é uma atividade multidimensional, multifacetada, que influencia muitas vidas e muitas atividades econômicas diferentes.

Nesse sentido, o turismo interfere na vida de muitas pessoas, gerando emprego e movimentando a economia, além disso, envolve e relaciona-se com outras áreas como a cultura, tecnologia, educação, comunicação, entre outras, que agregam valor à atividade turística e estimulam o desenvolvimento de pesquisas sobre a temática (Cooper et al., 2001). Entre estas, interessa aqui observar, especialmente, o lugar e a importância atribuída à dimensão experiencial do turismo e como ela se relaciona a escolha por modalidades de turismo como àquelas ofertadas pela plataforma Worldpackers.

\subsubsection{Turismo de experiência}

Entre os diferentes aspectos da área do turismo, focaliza-se aqui no turismo de experiência e suas implicações sociais. Na concepção antropológica, Turner e Bruner (1986 como citado em Pezzi \& Santos, 2012, p. 2) argumentam que "a experiência se trata da suspensão das relações cotidianas, a interrupção de papéis, em que o sujeito sofre um estranhamento em relação ao que lhe é familiar".

Outra definição é apresentada por Netto e Gaeta (2010, p. 44) que trata do turismo de experiência como "um tipo de turismo que pretende marcar o turista de maneira profunda e positiva, como as viagens de trabalho voluntário e a prática de esportes radicais (como salto de paraquedas)". Entende-se que a experiência vai muito além disso, por exemplo, pode se considerar a visita de uma família a terra de origem, que passa a ser algo marcante na vida daqueles indivíduos (Netto \& Gaeta, 2010).

Na obra "Turismo de Experiência" Netto e Gaeta (2010) aborda duas perspectivas estudadas pela sociologia, relacionados aos aspectos subjetivos da experiência dos viajantes: de um lado, uma vertente do turismo voltada às pessoas que viajam para fugir da sua rotina diária e, por outro lado, um viés interessado nos indivíduos que buscam viagens que possam ter um significado, isto é, que contribuam ao desenvolvimento interior "como uma forma de ampliar a mente, de experimentar o novo, o diferente para o enriquecimento próprio" (Netto \& Gaeta, 
2010, p. 44). A partir das análises realizadas nesta pesquisa, observa-se que é nesse segundo aspecto que os viajantes/voluntários da Worldpackers se encontram.

Ainda, de acordo com a percepção de Netto e Gaeta (2010, p. 47), a humanidade “chegou a um estágio em que poucas coisas simples lhe interessam. O que a grande maioria das pessoas busca é algo marcante, diferente, que fuja do senso comum e da (vidinha simples) que se desenha na correria do dia a dia”.

Cabe também ressaltar a importância atribuída ao fator experiencial no setor turístico e seu lugar no desenvolvimento da chamada "economia da experiência”. Pezzi e Vianna (2015) aproximam os estudos oriundos da administração, especialmente os do Marketing (Pezzi \& Santos, 2012), ao campo do turismo, para analisarem os fatores considerados mais memoráveis pelos turistas em suas experiências de viagem. Os autores salientam, ainda, a apropriação de tais concepções pela Política Nacional de Turismo, ao lançar, em 2010, o projeto intitulado "Economia da Experiência", cujo objetivo consistia em "[...] fazer com que o turista se sinta especial, e não apenas 'mais um', dentro de um grande grupo que se desloca guiado por rigorosas relações de comando que diluem a possibilidade de qualquer envolvimento afetivo com o destino" (Brasil, 2010, p. 7 como citado em Pezzi \& Santos, 2012, p. 174).

Nos últimos tempos cresceu o número de iniciativas ou alternativas para as pessoas que buscam aliar turismo e experiência, compartilhando experiências, de forma colaborativa ou cooperativa, além da Worldpackers, ainda há outras plataformas que proporcionam tal experiência, que são: AEISEC, Couchsurfing, Airbnb e Workaway.

Tendo como premissa a importância do setor turístico para a economia global, o surgimento de plataformas digitais de promoção e mediação turísticas figuram como interessante objeto analítico, podendo impactar o desenvolvimento econômico das comunidades, pelas lógicas comerciais a ela atreladas, bem como, o desenvolvimento social, se considerado o acesso ao turismo como um direito humano fundamental.

A tecnologia favorece ainda mais à ascensão do setor turístico e as plataformas digitais como, facebook, instagram, twitter, Youtube, entre outras, contribuem de forma positiva para este avanço (Cooper et al., 2001). Nessa ótica, observa-se como as tecnologias da informação e da comunicação se integram cada vez mais ao setor turístico, possibilitando o acesso à informações, a busca por destinos e, finalmente, o planejamento de viagens de forma totalmente digital (Cooper et al., 2001).

É no limiar entre esses campos, do turismo e da comunicação digital, que nos interessa investigar a emergência de plataformas digitais, como a Worldpackers, e entender em que 
medida elas influenciam ou favorecem o deslocamento de pessoas, o acesso a viagens e, consequentemente, contribuem à democratização do turismo.

\subsection{A comunicação digital na dinâmica do turismo contemporâneo}

Entende-se que o conhecimento e reconhecimento de muitas iniciativas desenvolvidas pelo setor turístico na atualidade são favorecidas e, muitas vezes, possibilitadas pelo advento da internet. Plataformas como a Worldpackers surgem e se desenvolvem pelo digital, tendo a facilidade de não precisar de um espaço e de interação necessariamente físicas - como as agências de viagens ou de intercâmbio tradicionais - e, ainda, possuem um alcance exponencialmente maior, graças às estratégias de divulgação virtuais.

Analisando de maneira retrospectiva, quando a banda larga de acesso à internet tornouse realidade na sociedade, a chamada Web 2.0 possibilitou a interação e participação on-line. A partir disso, observa-se o surgimento de redes sociais em todo o mundo, o que tornou cada vez mais comum as pessoas estarem conectadas por meio de diferentes plataformas digitais (Gabriel, 2010, p. 83). Na visão de Corrêa (2005), o assunto da comunicação digital foi se tornando mais visível e importante no âmbito da comunicação empresarial, sendo, portanto, imprescindível compreender o lugar das Tecnologias de Informação e de Comunicação (TIC's) na sociedade contemporânea, uma vez que, a área "abriu todo um campo de inovações, criatividade e dinamismo e também toda uma sucessão de posicionamentos, usos e escolhas que acabaram por criar incompreensões, inadequações e entraves no desenvolvimento da rotina comunicacional da empresa" (Corrêa, 2005, p. 97).

As TICs proporcionam uma nova visão da comunicação organizacional, pois, a partir da emergências dessas tecnologias, foi possível adequar e diferenciar o modo de comunicar, utilizando mecanismos e ferramentas digitais que favorecem a inovação e facilitam o relacionamento com diferentes públicos de interesse. É nesse contexto que a comunicação digital se desenvolve, entendida como "o uso das Tecnologias Digitais de Informação e Comunicação (TICs) e, de todas as ferramentas delas decorrentes, para facilitar e dinamizar a construção de qualquer processo de comunicação integrada nas organizações" (Corrêa, 2005, p. 105).

A conceituação de comunicação digital proposta por (Corrêa, 2005), refere-se às facilidades apresentadas pelas ferramentas digitais para a comunicação nas empresas. Além disso, os mecanismos, redes e meios digitais favorecem a comunicação de mão dupla, isto é, a troca de informações nos dois sentidos, da organização ao público e vice-versa, pois, de acordo com Farias (2011, p. 264) "a Comunicação digital trabalha de forma dialética, permitindo a 
interação e a troca de papéis entre emissores e receptores”. É muito comum confundir mídias sociais com redes sociais, uma delas trata-se da interação a partir de um interesse em comum, onde estão todas conectadas, esta, é a rede social, já a mídia social trata-se do conteúdo gerado pelas pessoas nas redes sociais, que em geral são: texto, imagem, vídeo, etc. (Gabriel, 2010, p. 202).

Já o facebook, o twitter e o instagram, são plataformas que ajudam as pessoas a se comunicarem e ampliarem suas redes de contatos. Portanto, no contexto da Worldpackers, as pessoas compartilham os conteúdos referentes a plataforma trocando informações com outros usuários destas plataformas, facilitando a disseminação de conteúdo (Gabriel, 2010, p. 202). As redes sociais geram uma gama de conteúdos e neste sentido o autor Henry Jenkins se refere a convergência, pelo "fluxo de conteúdos através de múltiplas plataformas de mídia, à cooperação entre múltiplos mercados midiáticos e ao comportamento migratório dos públicos dos meios de comunicação, que vão em quase qualquer parte em busca de experiências de entretenimento que desejam (Jenkins, 2009, p. 29).

No caso aqui analisado, da Worldpackers, entende-se tratar de um modelo de negócios que existe e se desenvolve graças ao digital. Ou seja, consiste em uma organização que opera através do trabalho em plataforma digital, dependendo das relações digitais e do ambiente em rede para subsistir. As plataformas digitais, segundo a visão operacional de Okano, Simões e Langhi (2020, p. 3), são "plataformas externas baseadas em softwares que consistem em base de código extensível que fornece a funcionalidade principal compartilhada pelos módulos que interagem com ela e as interfaces pelas quais eles interoperam".

Já em uma perspectiva crítica, Filgueiras e Antunes (2020, p. 60) asseveram sobre as novas formas de organização do trabalho associadas ao uso das tecnologias de informação e de comunicação (TIC) e as organizações que atuam sob a forma de aplicativos ou plataformas, afirmando que elas são, na verdade "estratégias de contratação e gestão do trabalho que mascaram o assalariamento presente nas relações que estabelecem". Nesse sentido, os autores realizam uma reflexão sobre as chamadas "novas relações de trabalho" instauradas nas organizações que operam sob o primado das tecnologias digitais, problematizando, especialmente, as condições precárias do trabalho digital (Casilli, 2020) na sociedade contemporânea, que derivam do modelo da economia de plataforma (Stefano, 2017).

Nessa pesquisa, visando investigar as principais modalidades de comunicação digital que possibilitam a interação entre a plataforma e os públicos de interesse (viajantes, voluntários e anfitriões), realizou-se uma análise exploratória no website da Worldpackers. A Comunicação entre anfitriões e voluntários realiza-se por meio da plataforma digital da Worldpackers por 
meio de uma ferramenta de "chat", que possibilita a troca de informações entre eles. Esta ferramenta é utilizada, também, com o objetivo verificar se o intercâmbio de trabalho está transcorrendo de maneira adequada, tanto para o viajante, como para o anfitrião que o aceitou.

Os viajantes podem, ainda, conversar com outras pessoas que estão cadastradas na plataforma, visualizar o perfil destes, e conhecer os relatos de experiência desses viajantes/voluntários com relação ao local (hospedagem) onde realizaram seus "intercâmbios de trabalho". Essa comunicação torna-se importante ao viajante interessado em candidatar-se aos locais ofertados pela Worldpackers, sobretudo para sanar dúvidas a respeito da localização, condições e serviços do lugar de hospedagem escolhido, e, assim, poderem escolher de forma mais segura as opções de voluntariado.

\section{METODOLOGIA}

Com relação à abordagem metodológica do estudo, realizou-se uma pesquisa exploratória (Gil, 2008), apoiada em pesquisa bibliográfica (Marconi \& Lakatos, 2003) e estudo de caso de caráter qualitativo (Yin, 2001), com foco na plataforma Worldpackers. Como técnicas de coleta de dados optou-se pela entrevista estruturada com o membro fundador da Worldpackers Brasil, Allan Formigoni, e, ainda, para a coleta de informações junto aos voluntários/viajantes da Plataforma, desenvolveu-se e aplicou-se um questionário virtual.

Visando conhecer a plataforma e compreender sua relação com o turismo, realizou-se uma entrevista estruturada, composta por 5 questões abertas, com o diretor de conteúdo e membro fundador da equipe Worldpackers, Allan Formigoni. Após um primeiro contato por $e$ mail, optou-se pelo desenvolvimento da entrevista através do aplicativo WhatsApp, que permite também o envio e registro de áudios.

Para a pesquisa direcionada aos viajantes/voluntários optou-se pela aplicação de um questionário, contendo 3 perguntas abertas e 4 fechadas, encaminhada no grupo do facebook chamado Worldpackers Community. O referido grupo publica conteúdos enviados pelos viajantes, ou ainda, por pessoas que tem interesse em voluntariado, sendo também um espaço para sanar dúvidas. O questionário foi elaborado e aplicado via Google Forms, no período de 01 a 10 de novembro de 2019, mas, antes da aplicação no grupo do facebook, efetuou-se um pré-teste com cinco (5) indivíduos que já tinham realizado voluntariado através da plataforma Worldpackers. A pesquisa contou com 15 respostas de viajantes/voluntários e, apesar da baixa adesão de respondentes, contribuiu para o conhecimento inicial desse grupo, a visão destes sobre a plataforma digital e sua relação com o turismo. 


\section{ANÁLISE E DISCUSSÃO DOS RESULTADOS}

\subsection{Experiência e acesso ao turismo: entrevista com o fundador da Worldpackers}

A pesquisa exploratória na plataforma, possibilitou conhecer o propósito da organização, e, ainda, através da entrevista com o membro fundador da Worldpackers, aprofundar as contribuições da plataforma acerca dos temas já mencionados anteriormente: como o impacto no turismo, vantagens/desvantagens e o diferencial do modelo de negócios colaborativo, em especial para o acesso às viagens.

Dessa maneira, foi possível analisar que a Worldpackers, é uma organização que atua através de uma plataforma digital, oferecendo intercâmbios de trabalho (voluntariado) e conectando anfitriões (hotéis, hostels, pousadas etc.) e viajantes/voluntários. O modelo de atuação da plataforma, consiste em conectar pessoas interessadas em viajar e anfitriões que buscam "voluntários" para determinadas tarefas, a fim de que estes possam realizar a troca de habilidades por hospedagem. Apresenta-se, portanto, como uma rede colaborativa que surge em 2014 com a premissa de oportunizar aos viajantes novas experiências, economizando e utilizando suas habilidades e capital intelectual, para atuar em diferentes locais turísticos pelo mundo.

Atualmente, a Worldpackers conta com três modalidades de voluntariado: 1) o intercâmbio de trabalho, baseado no voluntariado; 2) a experiência do "impacto social" que ocorre quando voluntários de qualquer lugar do mundo viajam para países onde há alguma carência social e, dessa maneira, ajudam em organizações sem fins lucrativos, escolas ou projetos sociais; e 3) através da participação em projetos ecológicos, trabalhando em eco vilas, fazendas e projetos de permacultura.

O modelo de negócios da Worldpackers funciona pela mediação da plataforma, que cobra dos viajantes /voluntários uma taxa de US\$ 49.00 dólares para que possam se candidatar a uma oportunidade de intercâmbio de trabalho. A partir disso, o viajante torna-se um "membro verificado" da plataforma, e a tarifa cobrada permite que se inscreva em outras vagas durante um ano, para viajar em qualquer lugar do mundo, quantas vezes quiser (Worldpackers, 2019).

De acordo com o relato de Allan Formigoni, a história da plataforma digital Worldpackers começa com Eric Faria, um dos fundadores, que atuava no setor contábil, mas que, insatisfeito com o estilo de vida que levava, buscava mudar de setor. Após uma viagem aos Estados Unidos (EUA) para aprender inglês, ele decide pedir demissão e inicia uma jornada pelo mundo, passando três anos viajando, conhecendo lugares, pessoas e idiomas. Da 
experiência com suas viagens, ele funda, juntamente com dois amigos, um hostel na cidade de San Diego (Califórnia), recebendo hóspedes do mundo inteiro sem cobrar pelas acomodações. A experiência dá certo, e então, em 2013, juntamente com Riq Lima (atualmente CEO da Worldpackers) começam a pensar na ampliação do negócio. Com a ajuda de um desenvolvedor de sites da Índia, o negócio inicia com a criação de uma plataforma online, lançada no dia 04 de fevereiro de 2014 com o nome de Worldpackers e cujo objetivo principal consistia na troca de habilidades por hospedagem (Worldpackers, 2019). ${ }^{3}$

Na visão de Allan Formigoni, há uma relação entre a Worldpackers e o setor de turismo, mas uma pequena contribuição, se comparada às grandes empresas do segmento turístico, por tratar-se de uma Startup que atende a um nicho específico, porém significativo, de viajantes: pessoas que não teriam condições financeiras de viajar pagando altos custos com hotelaria ou agências de turismo. Entende-se que um dos principais limitadores pessoais às viagens tornase a questão financeira, e, nesse sentido, a plataforma oferece uma alternativa econômica por meio da troca de hospedagem e outros benefícios - como por exemplo, refeições, passeios, descontos em bares e restaurante - por experiências, possibilitando uma redução de até $70 \%$ dos gastos. Por outro lado, é importante observar, conforme advertem Filgueiras e Antunes (2020, p. 61-62) que "é frequente a ideia de que o objetivo desses empreendimentos seria conectar a demanda de clientes por serviços específicos ofertados por trabalhadores/provedores" sendo que a "intermediação" operada pela plataforma digital "[...]permitiria que trabalhadores/as superassem as barreiras dos mercados de trabalho locais para potencialmente realizar tarefas de qualquer lugar do mundo para outro", ou, ainda, a promessa de que nessa modalidade de (intercâmbio de) trabalho por plataforma, as pessoas "[...]realizam as atividades apenas quando querem e onde querem" (ibid., p. 63).

Na opinião de Allan Formigoni o turismo tradicional pode ser muito degenerativo, pois as pessoas viajam para algum lugar, passam, e, dificilmente, deixam algo em troca. Ou seja, na visão dele, apesar de ter impacto na economia local, trata-se de um turismo transitório. $\mathrm{Na}$ opinião dele, a Worldpackers oferece mais alternativas de trocas, de aprendizado a partir da interação com moradores locais, de partilha de conhecimentos que podem deixar um legado para aquele lugar.

Apesar de atuar digitalmente, a plataforma possui apenas um escritório físico, em sua sede na cidade de São Paulo, no entanto sua atuação digital abrange mais de 160 países. De acordo com Allan, entre as principais vantagens de ser uma plataforma digital, aponta-se

3 História da Worldpackers. Recuperado de https://www.worldpackers.com/pt-BR/articles/a-historia-daworldpackers Acesso em: 21 out. 2019. 
primeiramente o custo, reduzidos com relação às operadoras ou agências de turismo que operam localmente, em diferentes cidades. Há, nesse caso, uma grande vantagem proporcionada pela ampliação geográfica que o ambiente digital proporciona. A plataforma digital Worldpackers conta com viajantes de mais de 160 nacionalidades e anfitriões em mais de 100 países, sem que a plataforma gaste um centavo com operações físicas em outros lugares. Logo, além dos custos reduzidos, outro atributo apresentado pelo fundador da plataforma seria o foco na "qualidade da experiência", bem como, uma maior liberdade de escolha entre as ofertas de locais e benefícios de hospedagem para o viajante-voluntário.

Se comparada com outras plataformas, a Worldpackers se diferencia por ser a única que oferece suporte - auxílio antes, durante e depois da viagem - caso o viajante necessite de informações, dicas ou eventuais contratempos, é possível acessar a equipe de suporte que irá ajudar e orientar o voluntário através do chat no próprio site. A plataforma oferece também o "seguro Worldpackers", que não se trata de um "seguro de viagem", mas uma garantia de que, ao candidatar-se para uma vaga de voluntariado, caso o viajante não encontre as condições esperadas junto ao seu anfitrião, a Worldpackers oferece uma "quota" de hospedagem em outro lugar, na mesma cidade, para que tenha tempo, e possa realizar o intercâmbio em outro estabelecimento.

A plataforma Worldpackers, nas palavras de Allan Formigoni, surge como uma oportunidade de viajar que, talvez, sem a existência da plataforma digital, as pessoas não tivessem acesso. Não importando o objetivo da viagem, algumas pessoas preferem fazer o voluntariado no exterior, outras apenas para tirar férias da faculdade, etc. Na visão do fundador, a Worldpackers, e outras plataformas de voluntariado, possibilitam que, mesmo em períodos de crise, as pessoas consigam realizar viagens, devidos aos baixos custos para a realização do intercâmbio, uma vez que, através da "troca de habilidades por hospedagem" acaba por custear sua estadia, em qualquer lugar do mundo, sendo esse o modelo principal de negócio da Worldpackers.

A entrevista com o fundador foi importante para esclarecer alguns aspectos sobre o surgimento da Worldpackers, sua relação com o setor do turismo, e ainda compreender o diferencial da plataforma em comparação com outras redes e modalidades de troca de habilidades por hospedagem.

Torna-se importante, no contexto desse trabalho, entender a atuação da Worldpackers, como uma mediadora entre empresas (anfitriões) e trabalhadores intercambistas (viajantes/voluntários), mas, também, refletir sobre as possíveis implicações que esse modelo de plataformização do trabalho (Grohmann, 2020) possa ter no mercado do turismo. 


\subsection{Resultados da pesquisa com os viajantes/voluntários}

O questionário, desenvolvido e direcionado aos viajantes/voluntários da plataforma, contribuiu para conhecer a percepção dos usuários sobre a Worldpackers, as práticas relacionadas ao turismo e a entender em que medida a realização de viagens nessa modalidade de "intercâmbio de trabalho", proporcionada pela plataforma, contribuiu para o acesso ao turismo.

A primeira pergunta tinha como objetivo saber a idade dos viajantes, sendo assim, as respostas foram: 66,7\% com idades de 18 a 25 anos, $20 \%$ com idades de 26 a 33 anos, 6,7\% com idades de 34 a 40 anos, e apenas $6,7 \%$ com mais de 40 anos.

A partir das respostas, foi possível perceber que a maioria dos respondentes possuía, em média, de 18 a 25 anos, portanto, podemos supor que, grande parte do público usuário da plataforma é composto por jovens, que utilizam o voluntariado para realizar uma viagem de férias, ou, ainda, que encontram na Worldpackers uma oportunidade de ter novas experiências.

Não podemos deixar de mencionar o público na faixa etária dos 30 anos ou mais, que também encontra na plataforma uma possibilidade de experimentar o turismo. Esse público, muitas vezes, é formado por pessoas que já trabalham e que, de alguma maneira, possuem uma renda econômica favorável, mas vislumbram nas modalidades oferecidas pela Worldpackers novos desafios, que se distanciam dos moldes tradicionais de viagens através de agências.

A segunda questão, buscou saber a cidade de residência dos viajantes, e as respostas foram diversificadas. Entre aquelas com maior frequência, 20\% apontaram a cidade de São Paulo e 13,3\% a de Porto Alegre/RS.

Como o caráter da pesquisa era qualitativo, também buscou-se entender como esses viajantes/voluntários conheceram a plataforma. A maioria das pessoas respondeu ter conhecido a Worldpackers a partir de amigos e pelas próprias redes sociais que a plataforma utiliza. Em termos percentuais, $26,6 \%$ dos viajantes responderam que a haviam conhecido a partir de indicação de amigos, 26,7\% pelas redes sociais e 13,3\% pelas propagandas/publicidade. Observa-se, a partir disso, que os viajantes da Worldpackers conheceram a plataforma, majoritariamente, por meio de networking, ou seja, indicação de parentes ou amigos, e ainda, pelas redes sociais, sejam elas, o faceboook, instagram, ou então, o Youtube.

A quarta pergunta procurou saber quais eram as facilidades/vantagens e dificuldades da plataforma digital em comparação com as agências de viagens. Esta foi uma pergunta aberta, e a partir dela foi possível observar semelhanças entre quase todas as respostas. Entre as respostas, destaca-se: 
Tem muito mais facilidade e vantagens do que dificuldades, você não paga por acomodação, você aprende coisas novas já que o voluntariado também serve pra isso, você faz amizades, conhece o lugar pelo olhar do morador da cidade e as vezes até faz uma grana no meio da viagem, vejo desvantagens só pra quem não tem esse estilo de vida, algumas pessoas não se adaptam e preferem realmente uma viagem com tudo planejado sem fugir do roteiro. Mas quem gosta de se aventurar acredito que o voluntariado é uma ótima alternativa, inclusive para aqueles que pretendem fazer intercâmbio, já que no voluntariado você também tem oportunidade de praticar um idioma novo (Viajante-voluntário 01).

Muitos responderam destacando, como aspecto positivo, a facilidade de acesso à plataforma. Outro ponto que apareceu em várias respostas, foi o aspecto econômico, conforme afirma um dos respondentes: “A vantagem é que é mais barato que agência de turismo e intercâmbio. A dificuldade são os problemas de convivência que você pode encontrar nos anfitriões" (Viajante-voluntário 02).

A quinta pergunta teve como objetivo saber o tempo que os viajantes/voluntários já conheciam a plataforma. Ao analisar as respostas mais relevantes, pudemos perceber que: $40 \%$ viajava pela Worldpackers há cerca de 2 anos, 33,3\% viajava pela Worldpackers há um ano, 13,3\% viajava pela Worldpackers há 4 anos, 6,7\% viajava pela Worldpackers há 3 anos. Deste modo, percebe-se que, quanto maior tempo de conhecimento e de uso da plataforma, maior a frequência de viagens. Além disso, como a plataforma surgiu há poucos anos, as pessoas ainda não possuem muito conhecimento sobre ela, porém com a intensificação recente da comunicação digital da Worldpackers, a partir de suas mídias sociais, é bem possível que essa realidade de modifique em breve.

As questões 6 e 7, foram desenvolvidas visando conhecer a frequência e o possível aumento da ocorrência das viagens antes e após o contato com a plataforma. Nesse sentido, a sexta questão, revelou que os viajantes/voluntários que viajavam apenas 1 vez ao ano, eram $60 \%$, outros $20 \%$ responderam que a frequência de viagens era de 2 a 3 vezes ao ano, 13,3\% afirmaram não viajar e o outros $6,7 \%$ respondeu que viajava raramente.

Já na pergunta 7 , foi questionada a frequência das viagens após conhecerem a Worldpackers. As respostas foram: 40\% dos viajantes conheceram de 2 a 5 novos lugares, $33,3 \%$ entre 1 e 2 lugares e 20,1\% conheceram de 6 lugares para mais. Levando em conta a resposta da pergunta 6 , percebe-se que os viajantes viajavam pouco antes de conhecerem a Worldpackers. Logo, confirma-se o aumento no número de viagens, possivelmente impulsionado pela realização de intercâmbios via plataforma.

Assim, nota-se um aumento na frequência de viagens após o engajamento (via voluntariado) com a plataforma. Pode-se inferir, a partir do levantamento, que a plataforma possibilitou o acesso ao turismo a esses viajantes, à medida em que mais pessoas puderam viajar 
e conhecer novos lugares, por meio da troca de experiências e competências com as instituições anfitriãs, de acordo com a proposta da Worldpackers.

Para findar o questionário com os viajantes/voluntários, optou-se por saber se eles acreditavam que a plataforma mudava a relação com as viagens e com o turismo. As respostas foram positivas e cada uma delas apresentava conteúdos semelhantes, que diziam respeito ao benefício do voluntariado em possibilitar viagens sem um alto custo, ou ainda, a respeito da experiência "enriquecedora" através dos intercâmbios de trabalho. Sobre esse tema, o viajante/voluntário 3 afirmou que:

\begin{abstract}
A imersão proporcionada pela convivência e trabalho, nesse tipo de turismo de voluntariado, leva a um novo tipo de forma de se fazer turismo, Você se sente parte do local ao qual está visitando, devido a quantidade de relações que são criadas durante as experiência de viajante-voluntário, e a realização de poder ser útil e obter novos aprendizados (Viajante-voluntário 03)
\end{abstract}

O questionário possibilitou analisar as contribuições mais latentes da plataforma Worldpackers para a democratização do turismo, as perguntas abertas permitiram ter conhecimento da opinião dos viajantes/voluntários sobre a plataforma, suas vantagens, desvantagens e benefícios. Portanto, com base no questionário aplicado a uma pequena amostra de viajantes usuários da plataforma, podemos considerar que a plataforma possibilitou o aumento no número de viagens, e, logo, um maior acesso ao turismo para esses viajantes/voluntários. Além dela, há outras plataformas digitais, com suas especificidades que também podem colaborar para a ampliação não apenas no consumo, mas também na oferta turística. Porém, conforme apontado pelo fundador da plataforma, bem como por viajantes, a Worldpackers apresenta como diferencial o suporte e seguro Worldpackers, um acompanhamento da viagem antes, durante e após a aplicação do viajante/voluntário, que pode conferir mais segurança na realização do intercâmbio.

\title{
5. CONSIDERAÇÕES FINAIS
}

O presente trabalho teve como objetivo geral, saber as contribuições da plataforma digital Worldpackers para a democratização do turismo. Para isso realizou-se uma pesquisa com foco na plataforma, e, nesse sentido, a revisão conceitual voltada à comunicação digital revelou-se fundamental na reflexão sobre o surgimento da plataforma digital, os usos da tecnologia nesse modelo de negócio e as possibilidades para o turismo. Da mesma forma, a análise dos públicos e das formas de relacionamento com estes, realizada pela plataforma 
através de diferentes mídias sociais, tornou-se indispensável para entender a atuação da Worlpackers e a forma como os viajantes/voluntários interagem entre si e com a plataforma.

Também foi importante conhecer e explorar outras alternativas que concorrem com o modelo de negócio analisado (AirbnB, AIESEC, CS), a fim de observar as singularidades, os diferenciais da Worldpackers com relação às demais, como, por exemplo: a troca de experiências e habilidades por hospedagem, a escolha de lugares para a realização das viagens e áreas de atuação, a possibilidade de realizar cursos para aprender técnicas de escrita e produção de conteúdo, entre outros.

O trabalho apresenta certo ineditismo, pois não há outras pesquisas sobre a plataforma Worldpackers, com aproximações entre a comunicação, a área do turismo e os aspectos da democratização. Dessa maneira, o estudo colabora para uma nova percepção das plataformas digitais, a partir do turismo e da comunicação e, embora tenha sido desenvolvido a partir de uma pesquisa aplicada e com um número reduzido de respondentes, colabora ao conhecimento desse universo e abre caminho para outras investigações que possam explorar o tema a partir de outras perspectivas teórico-analíticas.

Além da Worldpackers, entende-se ser importante conhecer e reconhecer a emergências de novas plataformas digitais de viagens. Percebe-se que esses modelos emergentes contam com um público de interesse específico, conforme exposto, por exemplo, em matéria recente publicada no Jornal Estadão ${ }^{4}$, em que destaca-se o surgimento de startups de viagens constituídas para atender nichos de mercado específicos, tais como: pessoas que enfrentaram algum problema, como assédio sexual, racismo, ou, ainda, idosos que não se sentiam à vontade na realização de intercâmbios para aprender idiomas. Tais pessoas podem viajar ou realizar intercâmbios por meio de empresas que visam hospedar grupos com características específicas, ou que tenham enfrentando problemas de preconceito, como proposto pelas startups Sister wave $^{5}$, diáspora.black ${ }^{6} \mathrm{e}$ a startup vivência.

A partir dessa investigação, percebe-se que o processo de "democratização" das viagens é gradativo, mas já vem ocorrendo desde o início do século XX, com a disseminação do uso do automóvel e do avião (Banducci \& Barretto, 2001). Portanto, esse trabalho exploratório, a partir da entrevista com o membro fundador da Worldpackers, bem como da coleta de informações junto aos viajantes/voluntários revelou que, em certa medida, a plataforma

${ }^{4}$ Estadão. De gays a idosos, negócios de turismo focam em nichos sociais. Recuperado de https://pme.estadao.com.br/noticias/geral,de-gays-a-idosos-negocios-de-turismo-focam-em-nichos-

sociais,70003023165. Acesso em: 11 nov. 2019.

${ }^{5}$ https://www.sisterwave.com/

${ }^{6}$ https://diaspora.black/ 
Worldpackers contribui para a democratização do turismo, se considerado o aumento na frequência de viagens e, portanto, o maior acesso ao turismo delas decorrentes.

Porém, destaca-se que a pesquisa deu conta de explorar apenas uma perspectiva possível, no estudo da relação entre a comunicação digital e a emergência de novas plataformas que oferecem relações e práticas diferentes de realização de viagens e consumo turístico. Pretendeu-se aqui olhar, a partir de uma ótica comunicacional, as possibilidades e desafios para o turismo, em especial ao acesso às experiências turísticas que decorrem do surgimento de plataformas digitais como a Worldpackers.

Outros caminhos de análise poderiam ser tomados, tal como, uma perspectiva crítica pelo viés da precarização do turismo, bem como um olhar sobre a fetichização do turismo (Conceição \& Londero, 2017), e que podem ser consideradas como abordagens analíticas para futuros estudos sobre o turismo a partir da emergência de novas plataformas digitais e modalidades colaborativas. Finalmente, observa-se a existência de diferentes análises possíveis, com relação ao Worldpackers e a partir da pesquisa aqui iniciada, focalizando, por exemplo, as estratégias comunicacionais utilizadas pela plataforma, a partir de construções de narrativas dos viajantes/voluntários utilizadas pelo Youtube, por exemplo, em uma perspectiva funcionalista, ou, ainda, refletindo a partir da ótica recente da plataformização do trabalho (Grohmann, 2020), em uma abordagem reflexiva, sobre as possíveis implicações que esse modelo de negócios, em plataformas digitais, possa ter no mercado do turismo e diretamente nas relações de trabalho nesse setor.

\section{REFERÊNCIAS}

Banducci, A., \& Barretto, M. (2001). Turismo e identidade local: uma visão antropológica. Papirus Editora.

Brasil. Lei $n^{o} 11.771$, de 17 de setembro de 2008. (2008). Dispõe sobre a Política Nacional do Turismo e dá outras providências. Brasília, DF: Ministério do Turismo.

Casilli, A. A. (2020). Da classe virtual aos trabalhadores do clique: a transformação do trabalho em serviço na era das plataformas digitais. MATRIZes, 14(1), 13-21.

Corrêa, E. S. (2005). Comunicação digital: uma questão de estratégia e de Relacionamento com públicos. Organicom, 2(3), 94-111.

Cooper, C., Fltecher, J., Wanhill, S., Gilbert, D., \& Shepherd, R. (2001). Turismo: princípios e práticas. (2a ed.). Porto Alegre: Bookman.

Conceição, R. A. M., \& Londero, R. R. (2017). Contribuições para crítica ao turismo de experiência: o fetichismo da mercadoria-turismo. Anais do ENPECOM 2017. Curitiba, PR, Brasil. 
Farias, L. A. (2011). Relações Públicas estratégicas. São Paulo: Summus.

Filgueiras, V., \& Antunes, R. (2020). Plataformas digitais, uberização do trabalho e regulação no capitalismo contemporâneo. In: Antunes, R. (Org.). Uberização, trabalho digital e indústria 4.0. São Paulo: Boitempo.

Gabriel, M. (2010). Marketing na era digital: conceitos, plataformas e estratégias. Novatec.

Gil, A. C. (2008). Métodos e Técnicas de pesquisa social. São Paulo: Editora Atlas.

Goeldner, C. R., Ritchie, J. R. B., \& Mcintosh, R. W. (2002). Turismo: princípios, práticas e filosofias. Porto Alegre: Bookman.

Grohmann, R. (2020). Plataformização do trabalho: entre dataficação, financeirização e racionalidade neoliberal. Revista Eptic, 22(1), 106-122.

Habermas, J. (1995). Três modelos normativos de democracia. Lua nova, 36, 39-53.

Jenkins, H. (2009). Cultura da convergência. Aleph.

Marconi, M. A., \& Lakatos, E. M. (2003). Técnicas de Pesquisa. São Paulo: Atlas.

Netto, A. P., \& Gaeta, C. (2010). Turismo de experiência. Senac.

Okano, M. T., Simões, E. A., \& Langhi, C. (2020). Plataformas de negócios digitais: o poder da transformação digital nos dispositivos móveis. Research, Society and Development, 9(2).

Pezzi, E., \& Santos, R. J. D. (2012). A experiência turística e o turismo de experiência: aproximações entre a antropologia e o marketing. Anais do VII Seminário de pesquisa em turismo do Mercosul da Universidade de Caxias do Sul - UCS, Caxias do Sul, RS, Brasil.

Pezzi, E., \& Vianna, S. L. G. (2015). A Experiência Turística e o Turismo de Experiência: um estudo sobre as dimensões da experiência memorável. Revista Turismo em Análise, 26(1), 165-187.

Santos, B. S. (2002). Democratizar a Democracia: Os caminhos da democracia participativa. Rio de Janeiro: Civilização Brasileira.

Stefano, V. M. (2017). Labour is not a technology-Reasserting the declaration of Philadelphia in times of platform-work and gig-economy. IUSLabor, (2), 1-17.

Yin, R. K. (2001). Estudo de Caso: planejamento e métodos. Porto Alegre: Bookman.

\section{FORMATO PARA CITAÇÃO DESTE ARTIGO}

BERTI, T., \& SANTOS, L. C. (2021). Voluntariado e democratização no acesso ao turismo por meio da plataforma digital Worldpackers. Revista de Turismo Contemporâneo, 9(2), 270-288. https://doi.org/10.21680/2357-8211.2021v9n2ID21838 